\title{
BMJ Open 'We both just wanted to be normal parents': a qualitative study of the experience of maternity care for women with learning disability
}

\author{
Reem Malouf, ${ }^{1}$ Jenny McLeish, ${ }^{2}$ Sara Ryan, ${ }^{3}$ Ron Gray, ${ }^{1}$ Maggie Redshaw ${ }^{4}$
}

To cite: Malouf R, McLeish J, Ryan S, et al. 'We both just wanted to be normal parents': a qualitative study of the experience of maternity care for women with learning disability. BMJ Open 2017;7: e015526. doi:10.1136/ bmjopen-2016-015526

- Prepublication history for this paper is available online To view these files please visit the journal online (http://dx.doi.org/10.1136/ bmjopen-2016-015526).

Received 14 December 2016 Revised 1 February 2017 Accepted 23 February 2017

CrossMark

For numbered affiliations see end of article.

Correspondence to

Maggie Redshaw;

maggie.redshaw@npeu.ox.ac.uk

\section{ABSTRACT}

Background: More women with learning disability (LD) are becoming mothers. Women with LD have rights to equal access to maternity care that meets their needs, however, many have poor pregnancy and birth outcomes compared to other women in the UK. Research is limited in this area.

Objectives: The aim of the study was to explore the lived experiences of pregnancy, childbirth, prenatal and postnatal care and services received by this group of women in the UK, including their expressed information and support needs relating to maternity care.

Methods: A qualitative study in which data were generated using in-depth semistructured interviews with learning disabled women who were pregnant or had given birth within the last 3 years in the UK; data were analysed using interpretative phenomenological analysis.

Results: 9 women with varying levels of cognitive impairment took part. 4 super-ordinate themes were identified: 'I hate being treated differently', 'I find it harder to understand than other people', 'We've had to prove ourselves' and 'Make sure you've got very good support around you'. Subthemes included: 'Negative attitudes and denial of choice', 'Understanding of normal care', 'Written information' and 'Being judged by professionals'.

Conclusions: With support from family and services, learning disabled women can become confident and successful parents. Maternity services should make reasonable adjustments when providing care to this group, including adapting to their individual communication and learning needs: allowing sufficient time in appointments, offering clear explanations of each aspect of care and sensitive support for autonomy and fully informed choice. Mothers who will be subject to a social care assessment of their parenting skills need clear information about the process, their choices and the level of skill they must demonstrate, as well as access to sufficient antenatal and postnatal support to give them the best possible chance of passing the assessment.

\section{Strengths and limitations of this study}

- In-depth qualitative interviews were undertaken with a group of people who generally do not often take part in research.

- The study has the potential to inform health professionals in maternity care and those specifically working with learning disabled women and their families.

- Easy to read participant information materials were specifically designed and used with this group.

- Limitations of the study include difficulties in accessing this population and unequal geographical distribution of participants.

\section{BACKGROUND}

People diagnosed with learning disabilities (or intellectual impairment) are commonly described as having difficulties in understanding information and communication, ${ }^{1}$ or deficits in social and practical skills and self-care. ${ }^{2}$ Learning disability (LD) is a condition that starts before adulthood which reduces the ability to learn complex or new information and to cope independently. ${ }^{1}$ In 2010, there were an estimated 1037400 adults in the $\mathrm{UK}$ with $\mathrm{LD}^{3}$ though many people may remain undiagnosed.

In the past, sterilisation and abortion were used to deny women with LD the possibility of becoming parents ${ }^{4-6}$ but the equal rights of learning disabled people to have children and to be supported in bringing them up are now enshrined in policy and legislation. ${ }^{7-11}$ However, women with LD are often faced with strong social and professional disapproval when they disclose their pregnancy ${ }^{8}$ ${ }^{12-15}$ and are more likely than other mothers to have their children removed and permanently placed outside the family home due to child protection or welfare concerns. ${ }^{16-18}$ 
People with LD experience poorer health outcomes and shorter life expectancy than the wider population, ${ }^{3}$ and mothers with LD and their babies are at higher risk of adverse outcomes during pregnancy and afterwards. ${ }^{8}$ 19-23 For example, research in Australia found that women with $\mathrm{LD}$ are more likely to have pre-eclampsia and to give birth to low birthweight babies who were admitted more frequently to neonatal intensive care unit. ${ }^{8}$ Moreover, women with LD may face barriers to accessing antenatal care including difficulties with public transport, with remembering appointments, and with understanding the purpose of the appointment. ${ }^{24}$

Women with LD have been found to be less satisfied with their maternity care compared with non-disabled women, particularly the interpersonal aspect of care as reflected in interactions with staff. ${ }^{20}$ The limited research on their maternity experiences describes unmet needs for accessible pregnancy information, consistent care and control over decisions relevant to their care.

\section{STUDY OBJECTIVES}

The main objective of our study was to better understand the individual experience of maternity care for women with LD, with a particular focus on access to maternity care, making choices, understanding information and feeling in control. In this way we would be able to reflect on the key support and services women with LD felt they needed during their pregnancy, birth and afterwards. We also aimed to increase the diversity of women whose views of UK maternity care are heard and for extracts from these interviews to be published at healthtalk.org, a freely available web resource of health experiences.

\section{METHODS}

The qualitative methodology was similar to that adopted by a number of studies involving people with LD. ${ }^{1425} 26$ Women's experiences were elicited using face-to-face, in-depth, semistructured interviews which allowed participants to express their views freely. The data were analysed using interpretative phenomenological analysis (IPA), a method suited to the in-depth analysis of the experiences and understanding of small group of participants $^{27} 28$ and aiming to draw out the unique and shared aspects of experience. ${ }^{29}$ The 'double hermeneutic' of IPA, in which the researcher tries to make sense of the participant trying to make sense of their world, ${ }^{27}$ enabled a multidisciplinary group of researchers to explore participants' lived experiences by combining the women's 'insider' perspectives with the researchers' 'outsider' perspectives. ${ }^{28}{ }^{30} \mathrm{~A}$ formal evaluation of intellectual ability was not undertaken in this study. The National Research Ethic Services (NRES) Committee for South Central-Berkshire ethical committee approved the study. The Research Ethics Committee Reference (REC) number: 12/SC/0495.

\section{Data collection}

Women were eligible to participate in the study if they had a LD and were pregnant or had given birth within the last 3 years in the UK. Recruitment of a convenience sample involved contacting advocacy groups, support workers, midwives and health visitors with an outline of the project and copies of the information leaflet (RM). Potential participants were approached by their care workers or workers in the support organisations, and the study was described. If a woman agreed to take part, her consent was sought to provide her contact details to the researchers who would visit and conduct the interview. A time was then arranged for the interviews and women were sent the accessible format illustrated 'easy-read' study information sheet, which was read to them when needed. A freephone number was also given to the women and their support workers for any further discussion about the study.

At the time of interviews, carried out by a researcher experienced in the field (SR), information was again provided about the study and what participation involved, including assurance that participants could withdraw from the study at any point. Questions were asked carefully and clearly with language like that used in the 'easy-read' information sheet. Written consent was obtained before the interview using an 'easy-read' consent form. Contextual information was collected on age, family circumstances and support. Interviews were video and audio recorded with participants' permission and before each interview photos and example clips were played using illustrative scenes of non-disabled women talking about pregnancy from healthtalk.org. Six interviews were conducted at the participants' homes, two in community centres and one in a hotel close to the participant's home.

A topic guide was used with a broad opening question asking women to talk about their experiences of being pregnant and giving birth, and subsequent questions exploring specific aspects of their experiences such as communication and interpersonal care. The participants also were asked in a general way about any changes they would like to make to their maternity care. All women were interviewed once, with interviews ranging from 40 to $100 \mathrm{~min}$. All interviews were fully transcribed, and copies sent to the interviewees and their care workers for comment. Minor changes were made by eight participants to some of the details provided.

\section{Data analysis}

The interview data were analysed thematically using IPA as described by Smith $2009 .^{28}$ This allows a very detailed analysis of a limited number of participant accounts and understandings as was appropriate for this kind of study. ${ }^{27}$ Each transcript was first analysed as an individual case before considering common themes. As each transcript was read and re-read, emergent themes were identified inductively and recorded using NVIVO software, while a manual $\log$ of researcher comments and 
reactions was also made. Emergent themes were clustered into groups under superordinate themes. This process was repeated for each transcript with previous transcripts reconsidered iteratively in the light of subsequently emergent themes. Finally, the themes from each transcript were combined.

\section{RESULTS}

\section{Characteristics of the study participants}

Nine women with LD participated in this study, eight of whom were reported by their support workers to have been diagnosed with mild-to-moderate LD. One participant had severe LD as reported by a family member. Three women also had a long-term health condition or physical disability and one had a serious mental health disorder. All participants were able to talk about their experiences, however, one was only able to give very short answers and one participant came to the interview with a set of notes as a prompt.

Participants were White and aged between 25 and 39 years (mean and median 30 years). Four women were living with their partners and five were no longer in a relationship with the father of their baby. One woman lived with her mother who cared for her child with her. At the time of the interview, one woman was pregnant (20 weeks gestation), four women had one child only, one woman had two children, one had three children, one had five children and one had one child and had also experienced a stillbirth. All children were reported to be non-disabled apart from one child who was diagnosed with LD. Two women had had their child removed from their care. Two women had some administrative work in their advocacy groups, and one woman worked as a waitress locally. All were receiving social services support, two women reported receiving mental health services support and four reported receiving support from their advocacy groups. Six said they had support from their family during their pregnancy and afterwards. Potentially identifying information has been removed to protect the anonymity of the participants, and pseudonyms are used.

\section{Emerging themes}

Four superordinate themes emerged from the analysis: 'I hate being treated differently', 'I find it harder to understand than other people', 'We've had to prove ourselves' and 'Make sure you've got...very good support around you'. The themes and subthemes are listed in table 1.

\section{'I hate being treated differently'}

The mothers expressed a great longing for 'normality', contrasting themselves with "normal parents" (Lisa) while believing that "women who have LD are not classed as normal" (Ellie). This theme considers how the mothers felt treated during their maternity care, and whether they felt this was 'normal'.
Table 1 Themes and subthemes identified in the analysis of interviews with LD women about their experience of care during pregnancy, childbirth and afterwards

\begin{tabular}{|c|c|}
\hline Key themes & Subthemes \\
\hline $\begin{array}{l}\text { 'I hate being treated } \\
\text { differently' }\end{array}$ & $\begin{array}{l}\text { Positive attitudes and } \\
\text { support for choice } \\
\text { Negative attitudes and denial } \\
\text { of choice } \\
\text { Understanding of normal } \\
\text { care } \\
\text { Suggestions for improvement }\end{array}$ \\
\hline $\begin{array}{l}\text { 'I find it harder to } \\
\text { understand than other } \\
\text { people' }\end{array}$ & $\begin{array}{l}\text { Written information } \\
\text { Other sources of information } \\
\text { Verbal communication with } \\
\text { healthcare professionals }\end{array}$ \\
\hline $\begin{array}{l}\text { 'We've had to prove } \\
\text { ourselves' }\end{array}$ & $\begin{array}{l}\text { Family reactions } \\
\text { Being judged by } \\
\text { professionals } \\
\text { Experiencing safeguarding } \\
\text { as discrimination }\end{array}$ \\
\hline $\begin{array}{l}\text { 'Make sure you've got very } \\
\text { good support around you' }\end{array}$ & $\begin{array}{l}\text { Family support } \\
\text { Professional support }\end{array}$ \\
\hline LD, learning disability. & \\
\hline
\end{tabular}

\section{Positive attitudes and support for choice}

Most of the mothers had enjoyed some or all of their antenatal care and spoke warmly about maternity staff who had supported them well during pregnancy and birth: "very good" (Dawn), "a great bunch" (Morgan), "very polite, very helpful" (Laura), "very well treated" (Ellie), "a lot of support" (Rachel) and "really quite supportive... very encouraging" (Jo). A friendly attitude was important to Sasha, who experienced it: "They can have a laugh. They're not all like stuck up," and to Katie, who did not: "[The midwife]'s grumpy. She doesn't smile or anything."

Other mothers were pleased with continuity of care: "I had the same midwife all the time so that was quite good" (Jo); or with proactive and personalised support: "[The midwife] phoned me up like, 'How's it going?'... And sometimes she'll come out to me if I can't make it" (Rachel). Morgan felt well supported by her community midwife who had some personal experience: "She had two children who had disabilities, so she understood what it was all about." Six of the mothers gave examples where they had successfully made choices about their maternity care, including to have an elective caesarean (Ellie and Laura); to decide on pain relief during labour (Rachel, Jo and Sasha); to have the father cut the umbilical cord (Morgan); to discharge themselves from hospital against medical advice (Jo and Rachel) and to request a change of health visitor (Jo). None reported any difficulty with attending antenatal appointments.

\section{Negative attitudes and denial of choice}

There were also negative experiences related to autonomy and staff attitudes. Lisa in particular felt that she 
was discriminated against by maternity staff, because "[they] think you're stupid...treat you as though you don't exist." She described how staff more than once discussed her care in front of her without including her in the conversation "like I wasn't even in the room," and how they told her that she would have to give birth by caesarean section because of a medical condition:

I would ask why was that and they were like, 'Oh, it's our choice. It's our decision.' And just felt like we didn't have a say in in how...we could have our son...felt like we were invisible really...no need for us to even be there because they'd already made a decision.

As well as feeling disempowered by her exclusion from decision-making, Lisa was ignored when she tried to find out where her newborn baby had been taken minutes after birth:

We kept asking, 'Where's he, where has he gone?'... Three hours after I had him, they brought him back to the ward and then they told us that he was in the special care ward because he needed his lungs looking at. And I asked them why they couldn't just tell us that's where they took [him] and they just walked away.

Morgan described how she was not able to make an informed choice about postnatal contraception before leaving hospital because she felt under pressure to make a decision: "I felt...they wanted me to give answers there and then without even giving me a chance to think about it. I felt pressurised into like getting the [longacting reversible contraceptive] injection when I didn't really want it. Cos if I said no I don't know what they would have said."

Rachel experienced poor care when she was left unattended for a long time during one of her labours and was spoken to disrespectfully by a midwife who addressed her as 'Speedy' following a quick labour: "They treat you...like a piece of dirt really. Like they don't really care." However, Rachel did not attribute poor care to her LD but to the fact that the staff were overworked, as did Jo: “They just haven't got enough staff really, it's not just purely because of having a learning disability...They're just rushed off their feet...So it's just a normal aspect of the NHS really." This contrasted with Lisa who observed how the midwives interacted with others to check whether she was being singled out for different treatments: "I hate being treated differently so like all through my appointments and on the ward I'd been watching how they respond to other people, and how they'd respond to other people was complete different to how they responded to me."

\section{Understanding of normal care}

The mothers' sense of themselves as outside the category of 'normal' may have led some of them to interpret what could have been ordinary aspects of maternity care as abnormal and discriminatory. For example, Katie disliked her midwife perhaps because she asked her the type of questions that all mothers are asked at their booking or first midwifery appointment: "She just wants to ask too-loads of questions. Just wants to be nosey in my private life." Some mothers were offered antenatal classes and others were not, consistent with the provision of antenatal education in some hospitals and not in others. ${ }^{31}$ Lisa assumed that only being offered antenatal classes starting when she was 8 months pregnant represented a deliberate exclusion: "I think they just thought, 'Oh, it's a pair of disabled people. It doesn't matter if they know what's going on or not." She also believed she was denied the conversations which "normal" women would have with their midwife during appointments, although similar concerns about brief and functional midwifery appointments have been expressed by many mothers without disabilities: ${ }^{31} 32$

I just felt I was being treated like a disabled person... because most women, they can go in and have a talk with the midwife and that, but even though the midwife was really nice and supportive...she didn't really talk much to me about things. It's like when like she checks to see if the baby is okay, she just goes, 'Yep, the baby is fine'. And then that's it.

\section{Suggestions for improvement}

Asked whether there was anything they would change about their maternity care, three mothers said there was nothing they would change. Three talked about staff attitudes and gaining information: "Just be more un-bossy, un-nosey. Just talk to me more about pregnancy. And actually smile" (Katie); and three talked about more staff training: "I'd like people to be more aware and learn and train about what a learning disability is so we don't get mistreated and misjudged" (Lisa). Rachel had made two formal complaints about her care and believed this had resulted in better treatment in her third pregnancy.

\section{'I find it harder to understand than other people'}

This theme considers a range of difficulties which the mothers described with understanding written and oral information about their maternity care and looking after a baby.

\section{Written information}

Ellie, Rachel and Sasha said they were able to understand the 'normal' information they were given. Morgan and Katie had been given 'easy read' information, designed for parents with learning disabilities, by their support worker or children's centre, and Katie could text her midwife with any questions. Laura asked a friend to help her with words she did not understand and Katie asked her mother. Lisa and Jo said they were not given any information: "I went through the whole pregnancy not really knowing what to do because I wasn't getting information off the doctors or the midwives" (Lisa), although Jo also said that someone came 
to her home to give her "the official labour talk" after the local antenatal classes were cancelled.

\section{Other sources of information}

Most of the mothers said that they had found the internet to be a good source of information on pregnancy and birth, especially the NHS Choices website; ${ }^{33}$ some had found this site accessible and others had used it with the support of their partner or family members: "There's bits of it that were quite confusing...I wasn't sure what I had to click onto" (Jo). They had found videos particularly useful. Those who had gone to antenatal or postnatal classes had found them "very useful" (Ellie), and Laura particularly valued being "showed how" to carry out baby care tasks such as bathing, nappy changing and bottle feeding in hospital. Katie had been able to practise with a 'Real Care Baby': "It just cries, and then you've just got to use this little tag thing near its belly button and you've just got to try and see if it needs rocking, feeding, or changing."

\section{Verbal communication with health professionals}

The mothers' experiences of understanding health professionals at their appointments were also mixed. Some did not have any difficulties, with Rachel describing how "[Midwives] were sort of like, help you out and tell you what you can and can't do, what you can and can't eat." Dawn was supported to communicate by her mother and Jo's partner helped her to understand at a scan. Lisa and Jo described situations where they had not understood something, but when they asked the health professionals to explain, their requests were ignored: "I said, 'I don't understand what you're talking about'. 'Oh, we haven't got the time for that, I'm just going to prod you and poke you and I'm going to go'" (Jo). Jo explained that she did not challenge this poor communication because "I know that they don't have any specific training for people like me, so I just left it at that." In contrast, when Morgan could not follow what was being said at a scan, she felt able to ask the radiographer for more help: "I couldn't really see that screen up at the top...So if they said, 'This is the...', I'm saying, 'Well, where? Cos I can't see it'. When they showed me on their computer bit, then I could see it or her...So they were really clear."

Lisa described how she signed a consent form for a caesarean without properly understanding it: "They just went through a consent form really quickly and then I signed that but I didn't understand what I was signing... And they didn't explain...the caesarean procedure or anything so I was just clueless." The consequence of this lack of adequate explanation was that her baby's birth was a very frightening experience: "Before the caesarean and all the way through the caesarean I was just shaking really badly because I was that scared because I just didn't know what was happening." For Lisa, this incident was part of a repeated pattern in which she felt that staff were deliberately withholding information from her: doctors "wouldn't explain why" they felt it was safer for her baby to be born by caesarean, a physiotherapist or doctor "wouldn't advise me on what else I could do to stop the pain," staff "wouldn't explain to us what jaundice was," midwives took her baby to the special care unit and "wouldn't tell us where they took him."

This was in contrast to Sasha's experience of midwives explaining placental abruption in terms she could understand: "They said that the placenta eruption means that your placenta moves away from your body whilst your baby's still inside. Instead of waiting for baby to come out, and then come out as well," and Dawn's understanding of having an anti-D injection because of her rhesus status: “[My baby]'s blood is different than mine, that's why I had a drug to stop it killing the baby off." Katie also said that her midwife made an effort to explain things that she did not understand: "She does try and explain to me. But I do find it hard to understand it. Because I've got a learning disability, so I find it harder to understand than other people." Jo had a health visitor who "explained things to me, so she was fine."

There were also some conversations recounted by mothers where it was apparent that the midwives had not communicated clearly, although the mother had not realised that she had not understood them. For example, midwives had advised Morgan against mixing breastfeeding and bottle feeding at birth, in line with the usual advice to enable breastfeeding to become well established before a bottle is introduced. Morgan had, however, understood this to mean that she should exclusively bottle feed: "I said I wanted to do both...I got told that it would mess up the baby's head really...So I just went on bottle-feeding her."

\section{'We've had to prove ourselves'}

This theme describes how almost all of the mothers felt that becoming a mother had been overshadowed by the requirement to demonstrate to others their ability to be good-enough parents: "For the last 8 months we've had to prove ourselves really. And we should n't have had to" (Morgan).

\section{Family reactions}

For Laura, this meant succeeding in the teeth of her family's expectations: "Most members of my family thought I'm not going to cope with a child. Even my Dad said that I wouldn't do it. But I proved him wrong" (Laura). Others were pleasantly surprised at the positive reaction and support from their family, for example Katie: "Not as I would have expected. My Grandad still doesn't like the idea...but everybody else seems to be fine with it."

\section{Being judged by professionals}

A bigger issue was the need to prove themselves to social workers concerned about safeguarding the welfare of their children. All the mothers had some involvement 
with social services, either for themselves as vulnerable adults, or for the children. Owing to their learning disabilities, two of the mothers had had to undergo an assessment of their parenting capabilities when their babies were born and were not allowed to care for their children independently as a result (Ellie had failed the assessment and Lisa had declined to go to a specialist residential unit for assessment). Rachel and Laura had social workers involved for reasons unrelated to their learning disabilities, and Morgan's baby had been referred to children's social services after an incident in hospital had triggered a safeguarding concern, but this had been poorly explained to her: "We would have understood from the beginning if they told us the reasons why. And they did n't."

A recurrent theme in many of the mothers' accounts was the strain and inequity of becoming a parent under the judgemental gaze of the health and social care professionals: "They were watching over my shoulder" (Rachel). Jo said that professionals had expected her to fail as a parent: "A lot of people within midwives and health visitors, they just look at you and they make assumptions"; but Rachel had received affirmation from the midwives that exceeded her self-perception: "[They] said that I was doing well. Which, I don't basically think that I was doing well. But I done well. They could see it. But I couldn't see it." Jo had decided that in the context of professionals looking for deficits, it was not safe to be honest about her postnatal emotions because "I thought if you said something how you's is exactly feeling, and if you was feeling a bit down that particular day, that they would use that against you." This was echoed by Sasha who accepted social workers' advice in order to avoid problems: "I just go along with them. Keep the peace. Otherwise it's never going to end."

For some mothers, this scrutiny was an unanticipated contrast to being treated 'normally' during pregnancy. Morgan described how "Afterwards, things started to change. Me and my partner were treated differently," and she found it particularly hard being judged on carrying out babycare tasks correctly when different professionals gave contradictory advice about what to do: "A lot of the things that the community healthcare assistant taught us was completely different to how we were shown in the hospital." Two mothers who did not have care of their children vividly described how stressful it had been to be constantly watched with their newborn child: "I couldn't cope and I felt under pressure...I was actually being monitored and watched every day, every time, everywhere in the assessment unit. And I didn't feel like I was at peace" (Ellie). Lisa found being scrutinised immediately after birth had undermined her ability to behave naturally:

We weren't allowed to do anything unless the midwife was supervising us...I felt too nervous to enjoy it...like when you bottle-feed and you just have this odd glance at your husband, or someone who knows it's a proud moment and I just found I had to fix my eyes on my son...I didn't feel I could look somewhere else in case I got marked down for it.

\section{Experiencing safeguarding as discrimination}

As well as the emotional pain of not being allowed to care for their children, these two mothers felt "guilty" (Lisa) and experienced distress at the disappointment of their dreams of parenthood: "This was something I've always been looking forward to. To being a mum" (Ellie). They both interpreted the decision that their babies should be looked after by the grandparents or the father as discrimination: "I felt like my rights were not heard as a mother with LD...they're always picking on us" (Ellie); "People aren't seeing past the learning disability...There's no reason for you to judge me on whether I can understand how to look after a baby or not" (Lisa).

Ellie's self-assessment was that "I was a fantastic mother" and she blamed the court which had awarded care to the father, her partner at the time, for not "thinking about me and obviously, not just the child." She had not been expecting this outcome: "I thought that instead of going to court that social services would work with me to support me and encourage me to keep my little girl." Lisa had also not understood the postbirth child welfare system. Having decided not to go to a mother and baby unit for support and assessment, she was nonetheless taken by surprise when social services said that she and her husband (who also had learning disabilities) would not be able to take their baby home from hospital. With hindsight she thought that this outcome was the inevitable result of her decision: "From the moment social services were involved, they always planned according to my husband's parent's care... that's where [the baby] was going because I refused to go in the mother and baby unit." Likewise Morgan was "not sure" whether social workers had told her that she might be monitored postbirth.

\section{'Make sure you've got...very good support around you'}

This theme considers how the mothers were aware that to succeed as parents they needed to have good support, and how several of the mothers who had been well supported were flourishing.

\section{Family support}

Some had this support from their partner or family members, and Morgan described how this was a formal part of her discharge plan from hospital: "It was agreed that I would go and stay with [my partner's] mum to start off with." Morgan's advice to other mothers was "Make sure basically you've got a good team of people around you and very good support around you." Ellie did not have family support and believed this had contributed to her losing care of her child: "At the time I pushed my family away because I fell out with them... Which was a mistake I made and regret." 
Laura had successfully managed a situation where her parents in law were "trying to take over" and had developed the confidence to make her own parenting choices: "I thought to myself, 'I need to do this for myself'...I tried their advice. Sometimes it worked, and sometimes it didn't. But I chose which option that I stuck to.”

\section{Professional support}

Most of the mothers also had substantial support in the community from social workers, health visitors, support workers, children's centres and voluntary sector agencies. Rachel had fought to keep her social worker when she moved to a different area: "I still wanted that support," and Morgan had argued for her support to be increased postnatally: "I also managed to get an extra day of support as well." Sasha described her social worker a source of support rather than scrutiny: "She just comes over, trying to get a bigger house...they're good, when you need them"; and she described the qualities in a social worker that she liked: "She's calm... She don't just take in what she wants to hear and then don't do nothing about it, she actually listens." She identified the dilemma that the support, which she wanted, came with unsolicited advice, which could be useful but could also feel intrusive: "I don't mind them being around, because they're quite helpful. But it does bug me a bit, because I know that I can look after [the children]. But they give you good tips, like on what to do, and what advice to go for...I like the support from them."

Jo and her partner had exercised autonomy as parents when they decided not to follow the health visitor's advice about waking their baby up to feed her, instead devising their own successful solution to her falling weight; she noted that the health visitor did not like this, but "we still did it." She had likewise made up her own mind to disregard the baby care advice from epilepsy specialists, after she had a fit shortly after birth: "I observed the situation for a while and then just went back to normal." Jo was one of several mothers who described how they had become confident and successful parents: "[Health professionals] said, 'Oh, you're not going to do well', so I didn't have a lot of encouragement at all. And so I proved them all wrong."

Lisa and Ellie said that they had not been given enough support to learn to be a mother before being assessed on their parenting; Ellie felt that "Social services could have...put me on to parenting courses and give me the support that I need and encouragement to manage to look after my daughter as a mother." Despite separation from their children, both were working hard to maintain their identities as mothers: "I've been writing letters every day to my daughter, so that when she's older she can read them and understand and know that...if I fight and I don't win that I've tried my best for her" (Ellie). This had been challenging for them; Ellie said she had forgotten her child's birthday and Lisa said that "I kept forgetting I was a mum because I couldn't look after my son."

\section{DISCUSSION}

The mothers who took part in this study had varying levels of LD and diverse experiences within the maternity services. Most were positive about their antenatal and intrapartum care and the attitude of their midwives, consistent with Redshaw et $a l^{20}$ finding that $93 \%$ of mothers with learning disabilities rated their antenatal care as good or better. Although one mother had the clear impression that healthcare professionals were expecting her to fail (which she did not), none had had their right to be a parent challenged by maternity practitioners. This is in line with the findings of a small qualitative study of English midwives' attitudes and experiences $^{34}$ but contrary to a survey of Swedish midwives, a third of whom partly or wholly agreed that women with learning disabilities should not have children. ${ }^{15}$

Research and national guidance has repeatedly emphasised the importance of assessing a learning disabled parent's support needs, providing accessible information in a variety of easy read or audio-visual formats, offering longer appointments and checking that information given has been understood. ${ }^{811} 1735$ Despite the clear duty imposed on services under the Equality Rights Act $(2010)^{10}$ to make 'reasonable adjustments' to meet the needs of disabled people, several mothers had experienced rushed appointments where their communication needs were not met and they were left feeling confused and marginalised. Two said they had been denied explanations when they specifically asked for them. None had been given easy-read pregnancy and birth information by maternity practitioners (although some had received this from other sources). This failure to adapt standard care to meet mothers' needs reflects earlier research findings. ${ }^{20} 24$ 36-38 Mothers' suggestions that maternity professionals need more training are echoed by midwives themselves, who feel out of their depth when trying to communicate with and appropriately support parents with learning disabilities. ${ }^{34} 363839$

In situations where a midwife had not checked whether the mothers had understood what was said to them, some mothers were left to draw potentially mistaken inferences from midwives' words or behaviour. Particularly in some cases where mothers felt highly conscious that they were not seen as 'normal' women, their LD appeared to become a lens through which every encounter was understood, and what may have been ordinary aspects of maternity care were therefore interpreted as discriminatory. This highlights the importance of careful explanations of all aspects of maternity care, including explaining what the usual offer of care is and any reasons for different treatments.

Some mothers had attended antenatal classes and found the hands-on learning very helpful. ${ }^{36}$ Three more 
mothers had been keen to attend classes, in contrast to a mother in Porter's et al study, ${ }^{37}$ who was embarrassed to attend a group. Without accessible written information or explanations from midwives, some mothers described how they relied instead on family members, as in Quartermaine, ${ }^{40}$ and the internet to find information.

Although six of the mothers recounted situations in which their right to make choices about their care had been respected (including mode of birth), two described how professionals either made a decision for them (for birth by elective caesarean) or did not ensure that they gave genuine informed consent (to caesarean birth or a contraceptive injection). Unlike earlier studies, none of the mothers had experienced maternity practitioners inappropriately seeking consent from a companion. ${ }^{36}$ Two mothers had encountered disrespectful attitudes from midwives. Lisa in particular had a range of frustrating and disempowering encounters with maternity staff that had left her feeling marginalised and 'invisible', lacking information she needed about pregnancy, birth and parenting, feeling denied aspects of care she believed were given to 'normal' mothers and believing that a large number of professionals had withheld information from her. Cox et $a l^{41}$ describe how specialist doulas work with expectant mothers with learning disabilities during pregnancy, birth and up to 6 months afterwards, supporting them to understand their pregnancy and to learn parenting skills, and acting as a 'translator' with professionals. This type of personalised, empowering support could have transformed Lisa's maternity experience and her understanding of it. This might also allow a safe space in which mothers could feel able to express any feelings of depression or low mood that they may not be able to disclose to health professionals.

Consistent with many other studies of learning disabled parents, ${ }^{25} 36404243$ many of the mothers in this study felt that they could not take motherhood for granted: they had to prove to the authorities and some family members that they were able to be suitable parents. Being supervised and judged by maternity professionals and social workers was stressful and disempowering, particularly for the three mothers who had been assessed at or shortly after birth. They were unclear what standards of behaviour they were being judged against, a process described by Booth and Booth ${ }^{16}$ as "like playing a game without being told the rules." They were also disadvantaged by receiving contradictory advice from professionals. ${ }^{17}$ For the mothers about whom there were child protection or welfare concerns, it was a shock to experience the difference in their treatment between pregnancy (when, as a vulnerable adult, their needs were central to professionals' planning and support), and after birth (when their child's needs displaced their needs as the focus of professionals' duties).
It has been argued that parents with learning difficulties "are disproportionately represented in care proceedings around the world," 16 but this has been challenged by a review of case files from 10 local authorities in England which found that there "was no evidence to suggest that parental learning disability in itself was the reason children were removed from their parents' care" and that removing children was used as a "last resort" after "a substantial input of services." ${ }^{44}$ The two mothers in our study who formally did not have care of their children understood their loss straightforwardly as discrimination by social services and the court. They were comfortable with the language of their rights as a parent with learning disabilities but did not show any awareness that the best interests of their child might not always be identical with their rights as a mother; or that where there were child welfare concerns, professionals had a specific duty to consider "how capable each of [the child]'s parents...is of meeting [the child]'s needs" (Children Act 1989, section $1^{45}$ ); or that a father has an equal right with a mother to be the primary carer following relationship breakdown. Instead they felt failed by services that had not sufficiently taught and supported them to be parents. Neither had been expecting the outcome and their distress was compounded by not having understood how the child welfare system might work in their situations. This system lacks transparency, given that the courts themselves continue to develop case law on the fundamental rights of learning disabled parents to "parent with support," 46 while accepting that there will be individual situations where no amount of support will enable the parents to provide their children with adequate care. ${ }^{47}$

All the mothers acknowledged that they needed support to gain confidence and succeed as parents, either from their families, or from social workers and other support workers. ${ }^{17}$ Some accepted that the price of this support was parenting advice, which might sometimes be useful and other times intrusive. A sense of power imbalance ${ }^{37}$ did not affect all mothers equally: some showed a sophisticated ability to negotiate the health and social care systems and their own family networks to get the support they wanted while ignoring unsolicited advice. They might do this covertly, to "keep the peace," or overtly, exercising their own responsibility as parents. The confidence with which some of these mothers managed their parental role, their choices and their relationships with service providers is very different from the experiences of mothers with learning disabilities reported in earlier research, which has tended to emphasise negative and disempowering experiences. ${ }^{48}$ It seems that the LD advocacy movement has achieved a great deal in normalising parenthood as a choice for people with learning disabilities, in the 20 years since Brown challenged services to see that women with learning disabilities are "women first" and "mind about the things other women mind about," including motherhood. ${ }^{49}$ 


\section{Strengths and limitations}

It was a strength of this study that it involved in-depth qualitative interviews with a group of women who do not often take part in research, following a careful and lengthy process of engagement with $\mathrm{LD}$ support and advocacy groups. The study used easy read participant information materials specifically designed for women with LD. The chosen analytic method, IPA, enabled consideration of mothers' subjective experiences with the meanings the experiences had for them, and also a critical analysis of what may have lain behind some of those experiences and meanings.

There were also some limitations. A convenience sample was used as gaining access to this group of participants was not easy and support organisations and family members acted as gatekeepers. One reason this group of women were reluctant to be approached directly appeared to be the assumption that researchers would assess their capacity and question their parenting ability. Others whose children had been removed may have felt reluctant to recall their maternity experiences.

\section{CONCLUSIONS}

Maternity professionals should be aware that the diagnosis of 'learning disability' masks a wide range of abilities, expectations and experiences, and that with support from family and services, women with LD can become confident and successful parents. In order for mothers with LD to have a 'normal' experience of the transition to motherhood, maternity services must make reasonable adjustments, including adapting to individual communication and learning needs, and taking the time to check that they have fully understood. It is important that each aspect of maternity care is clearly explained, so that the mother can understand what 'normal' care is like and is supported to make fully informed choices. Mothers who will be subject to a social care assessment of their parenting skills need clear information about the process, their choices and the level of skill they must demonstrate, as well as access to sufficient antenatal and postnatal support to give them the best possible chance of passing the assessment.

\section{Author affiliations \\ ${ }^{1}$ National Perinatal Epidemiology Unit, University of Oxford, Oxford, UK \\ ${ }^{2}$ Policy Research Unit in Maternal Health and Care, National Perinatal Epidemiology Unit, University of Oxford, Oxford, UK \\ ${ }^{3}$ Department of Primary Care, University of Oxford, Oxford, UK \\ ${ }^{4}$ Nuffield Department of Population Health, NPEU, Oxford, UK}

Acknowledgements The authors thank all the women who agreed to take part in the study. They also thank members of the advocacy groups, midwives and social workers who put them in touch with these women.

Contributors MR, RG and RM designed the study. RM contacted the advocacy groups, support workers and health professionals, made visits and gave talks about previous disability research and the planned study. RM and SR undertook the visits, and SR carried out the interviews. JM undertook the main analysis supported by MR and RM. JM, MR and RM drafted the manuscript, and all authors commented and approved the final version.
Funding The study was funded by the Policy Research Programme in the Department of Health.

Disclaimer The views expressed are not necessarily those of the Department of Health.

Competing interests None declared.

Ethics approval National Research Ethic Services (NRES) Committee for South Central-Berkshire Ethical Committee approved the study. The Research Ethics Committee Reference (REC) number: 12/SC/0495.

Provenance and peer review Not commissioned; externally peer reviewed.

Data sharing statement The sensitive interview data collected will not be available for data-sharing. Selected recordings may be made available on the Health Experiences website.

Open Access This is an Open Access article distributed in accordance with the Creative Commons Attribution Non Commercial (CC BY-NC 4.0) license, which permits others to distribute, remix, adapt, build upon this work noncommercially, and license their derivative works on different terms, provided the original work is properly cited and the use is non-commercial. See: http:// creativecommons.org/licenses/by-nc/4.0/

\section{REFERENCES}

1. Department of Health. Valuing people: a new strategy for learning disability for the 21st Century. London: The Stationary Office. https:// http://wwwgovuk/government/uploads/system/uploads/attachment data/file/250877/5086pdf (accessed May 2016).

2. American Association of Psychiatric. Diagnostic and statistical manual of mental disorders. 5th edn. Alexandria (VA): American Counseling Association, 2003.

3. Emerson E, Baines S. Health inequalities \& people with learning disabilities in the UK: 2010. Learning Disabilities Observatory. http:// wwwimprovinghealthandlivesorguk/uploads/doc/vid_7479 IHaL2010-3HealthInequality2010pdf (accessed August 2016).

4. Hamilton C. Sterilisation and intellectually disabled people in New Zealand-still on the agenda? Kōtuitui: NZ J Soc Sci Online 2012;7:61-71.

5. Hamilton C. Sterilization and intellectually disabled people in New Zealand: rights, responsibility and wise counsel needed. Kōtuitui: NZ J Soc Sci Online 2015;10:36-45.

6. Roy A, Roy A, Roy M. The human rights of women with intellectual disability. J R Soc Med 2012;105:384-9.

7. Mitra M, Parish SL, Clements KM, et al. Pregnancy outcomes among women with intellectual and developmental disabilities. Am J Prev Med 2015;48:300-8.

8. McConnell D, Mayes R, Llewellyn G. Women with intellectual disability at risk of adverse pregnancy and birth outcomes. $J$ Intellect Disabil Res 2008:52:529-35.

9. Department of Health. Valuing people now: a new three-year strategy for people with learning disabilities. London: The Stationery Office. http://base-ukorg/sites/base-ukorg/files/[user-raw]/11-06/ valuing_people_now_strategy_pdf (accessed October 2016).

10. Equality act. London: HMSO, 2010.

11. Department of Health \& Department for Education \& Skills. Good practice guidance on working with parents with a learning disability. http://wwwdmuacuk/documents/health-and-life-sciences-documents/ nursing-and-midwifery/goodpracticeinparentingsupport2013pdf (accessed 10 Aug 2016).

12. Aunos M, Feldman M. Attitudes towards sexuality, sterilization, and parenting rights of persons with intellectual disabilities. J Appl Res Intellect Disabil 2002;15:28-296.

13. Cuskelly M, Bryde R. Attitudes towards the sexuality of adults with an intellectual disability: parents, support staff, and a community sample. J Intellect Dev Disabil 2004;29:255-64.

14. Mayes R, Llewellyn G, McConnell D. Misconception: the experience of pregnancy for women with intellectual disabilities. Scand J Disabil Res 2006;8:120-31.

15. Höglund $B$, Larsson $M$. Struggling for motherhood with an intellectual disability - a qualitative study of women's experiences in Sweden. Midwifery 2013;29:698-704.

16. Booth $\mathrm{T}$, Booth W. Parents with learning difficulties in the child protection system experiences and perspectives. J Intellect Disabil 2005;9:109-29.

17. Tarleton B, Ward L, Howarth J. Finding the right support. A review of issues and positive practice in supporting parents with learning difficulties and their children. London: Baring Foundation, 2006. 
18. Elvish J, Hames A, English S, et al. Parents with learning disabilities: an audit of referrals made to a learning disability team. Learn Disabil Rev 2006;11:26-33.

19. Parish SL, Mitra M, Son E, et al. Pregnancy outcomes among U.S. women with intellectual and developmental disabilities. Am J Intellect Dev Disabil 2015;120:433-43.

20. Redshaw M, Malouf $\mathrm{R}$, Gao $\mathrm{H}$, et al. Women with disability: the experience of maternity care during pregnancy, labour and birth and the postnatal period. BMC Pregnancy Childbirth 2013;13:174.

21. Llewellyn G, McConnell D, Mayes R. Health of mothers with intellectual limitations. Aust N Z J Public Health 2003;27:17-9.

22. Šumilo D, Kurinczuk JJ, Redshaw ME, et al. Prevalence and impact of disability in women who had recently given birth in the UK. BMC Pregnancy Childbirth 2012;12:31.

23. Goldacre AD, Gray R, Goldacre MJ. Childbirth in women with intellectual disability: characteristics of their pregnancies and outcomes in an archived epidemiological dataset. $J$ Intellect Disabil Res 2015;59:653-63.

24. Gaudion A, Godfrey C, Cutts H, Homeyard C. Mothers with learning disability: access, information provision and ongoing engagement with antenatal care. A pilot project developing antenatal recourses. The Polyanna Project. http://thepolyannaprojectorguk/resources/ polyanna_project-mothers_with_a_learning_disabilitypdf (accessed August 2016)

25. Mayes R, Llewellyn G, McConnell D. "That's who I choose to be": the mother identity for women with intellectual disabilities. Womens Stud Int Forum 2011;34:112-20.

26. Baum S, Burns J. Mothers with learning disabilities: experiences and meanings of losing custody of their children. Tizard Learn Disabil Rev 2007;12:3-14.

27. Smith JA. Reflecting on the development of interpretative phenomenological analysis and its contribution to qualitative research in psychology. Qual Res Psychol 2004;1:39-54.

28. Smith JA, Flower $\mathrm{P}$, Larkin M. Interpretative phenomenological analysis: theory, method and research. Qual Res Psychol 2009;6:346-7.

29. Hood R. Combining phenomenological and critical methodologies in qualitative research. Qual Soc Work 2016;15:160-74.

30. Larkin M, Watts S, Clifton E. Giving voice and making sense in interpretative phenomenological analysis. Qual Res Psychol 2006;3:102-20.

31. Redshaw M, Henderson J. Safely delivered: a national survey of women's experience of maternity care 2014. Oxford: National Perinatal Epidemiology Unit. https://wwwnpeuoxacuk/downloads/ files/reports/Safely\%20delivered\%20NMS\%202014pdf

32. McLeish J, Redshaw M. 'We have beaten HIV a bit': a qualitative study of experiences of peer support during pregnancy with an HIV Mentor Mother project in England. BMJ Open 2016;6:e011499.

33. NHS. NHS choices website. http://www.nhs.uk/Conditions/ pregnancy-and-baby/pages/pregnancy-and-baby-care.aspx (accessed September 2016)

34. Castell E, Kroese B. Midwives' experiences of caring for women with learning disabilities-a qualitative study. Midwifery 2016;36:35-42.
35. National Collaborating Centre for Women's and Children's Health. Pregnancy and complex social factors: a model for service provision for pregnant women with complex social factors. London: NICE, 2010. https://www.nice.org.uk/guidance/cg110/resources/pregnancyand-complex-social-factors-a-model-for-service-provision-forpregnant-women-with-complex-social-factors-35109382718149 (accessed June 2016).

36. Begley C, Hames A, Lalor J, et al. The strengths and weaknesses of publicly-funded Irish Health Services Provided to Women with Disabilities in Relation to Pregnancy, Childbirth and Early Motherhood School of Nursing and Midwifery, Trinity College Dublin. https://nursing-midwiferytcdie/assets/publications/pdf/ nda-report-final-2010pdf (accessed September 2016).

37. Porter E, Kidd G, Murray N, et al. Developing the pregnancy support pack for people who have a learning disability. $\mathrm{Br} J$ Lear Disabil 2012;40:310-17.

38. Höglund $B$, Lindgren $P$, Larsson M. Midwives' knowledge of, attitudes towards and experiences of caring for women with intellectual disability during pregnancy and childbirth: a cross-sectional study in Sweden. Midwifery 2013;29:950-5.

39. Beake S, Clark LL, Turner T, et al. A mixed methods study to develop and pilot a competency assessment tool to support midwifery care of women with intellectual disabilities. Nurse Educ Today 2013;33:901-6.

40. Quartermaine D. ed. Maternity services for women with learning difficulties: a report of a partnership of midwives, community nurses and parents. London: The Maternity Alliance, 1999.

41. Cox R, Kroese BS, McGarry A. Pregnancy, birth and postnatal support for women with intellectual disabilities: the Can Do Doula model. Int J Birth Parent Educ 2015;2:19-22.

42. Booth $\mathrm{T}$, Booth W. Unto us a child is born: the trials and rewards of parenthood for people with learning difficulties. Aust $N Z J$ Dev Disabil 1995;20:25-39.

43. Sheerin FK, Keenan PM, Lawler D. Mothers with intellectual disabilities: interactions with children and family services in Ireland. Br J Learn Disabil 2013;41:189-96.

44. Cleaver $\mathrm{H}$, Nicholson D. Parental learning disability and children's needs: family experiences and effective practice. London Department for Children, Schools and Families. http:// webarchivenationalarchivesgovuk/20130401151715/https:/ wwweducationgovuk/publications/eOrderingDownload/ DCSF-00273-2008pdf (accessed June 2016).

45. Children Act. London: HMSO, 1989.

46. Re $G$ and $A$ (care order: freeing order: parents with a learning disability) [2006] NI Fam 8. http://wwwcourtsnigovuk/en-gb/judicial\% 20decisions/publishedbyyear/documents/2006/2006\%20nifam\%208/ j_j_gilc5486htm (accessed September 2016).

47. Re D. (A Child) (No 3) [2016] EWFC 1. https://wwwjudiciarygovuk/ judgments/re-d-a-child-no-3/ (accessed September 2016).

48. Homeyard C, Montgomery $E$, Chinn D, et al. Current evidence on antenatal care provision for women with intellectual disabilities: a systematic review. Midwifery 2016;32:45-57.

49. Brown $\mathrm{H}$. Ordinary women: issues for women with learning disabilities. Br J Learn Disabil 1996;24:47-51. 